Article

\title{
The Sustainable Role of the E-Trust in the B2C E-Commerce of Vietnam
}

\author{
Yongrok Choi * (1D) and Do Quynh Mai \\ Global E-Governance Program, Inha University, Inharo 100, Nam-gu, Incheon 402-751, Korea; \\ doquynhmai1812@gmail.com \\ * Correspondence: yrchoi@inha.ac.kr; Tel.: +82-32-860-7760; Fax: +82-32-876-9328
}

Received: 22 December 2017; Accepted: 17 January 2018; Published: 22 January 2018

\begin{abstract}
Vietnam, as a new emerging market, especially in e-business, has been promoting its emerging e-commerce market in Southeast Asia using aggressive players such as Lazada. Nonetheless, Vietnam has strong cultural background of risk-averse attitudes, like other developing countries, thereby deferring sustainable transformation into the e-business revolution. Therefore, it is necessary to examine the factors leading to the sustainable performance of e-commerce businesses, because highly risk-avert attitudes still cause many problems due to low levels of trust. In this perspective of trust, this research may contribute to promoting Vietnamese online shopping trends and suggesting ways for sustainable business to achieve success in $\mathrm{B} 2 \mathrm{C} \mathrm{e}$-commerce. The purpose of this research is to examine whether or not the characteristics of e-service quality (usefulness, convenience, security, responsiveness, and assurance) have a positive influence on customer loyalty, one of the sustainable success factors in this growing e-commerce industry in Asian markets. Using questionnaires and structural equation modelling, we concluded that it is crucial to promote e-trust as a vital element, because it lacks, in the short-run, an initial e-trust.
\end{abstract}

Keywords: service quality; trust; customer loyalty; Lazada; structural equation modeling; partial least structure

\section{Introduction}

Ever since the birth of the internet in the 1990s, online commerce has taken the world by storm. Empowered by the internet, e-commerce quickly spread out to most industries, as enterprises found it an effective method for business performance. E-commerce, which can be simply defined as the utilization of the internet to facilitate and execute business transactions, is a cost-optimized method to promote and run a business [1]. As e-commerce, represented by business to consumer (B2C) type of online shopping mall, has gained popularity all around the world, its role for changing our society as well as cultural norms has become much more important [2]. According to the Global B2C e-commerce report 2016 by E-commerce Foundation, around 2.5 billion consumers in the world found their way to the internet, and the majority of them purchased goods and services online for a total amount of 2671 billion USD. Asia-Pacific and North America are among the top regions for the highest positions, at a total B2C e-commerce turnover of 1057 billion and 644 billion USD, respectively in 2016 [3].

Vietnam, as an emerging e-commerce market in Southeast Asia, has witnessed an impressive expansion. In 2015, the Vietnamese e-commerce market was worth 4.07 billion USD, and it is expected to rise 20 percent per year to reach 10 billion USD by 2020, according to Vietnam e-Commerce and Information Technology Agency [4]. The Vietnamese domestic e-commerce playfield has been more and more crowded, led by the major players such as Lazada, Tiki, Sendo, etc. Based on the globally successful model of Amazon and Alibaba, Lazada was launched in Vietnam in 2012, and it became a leading B2C e-marketplace in Vietnam e-commerce market. In Vietnam, e-commerce market has an enormous potential to grow bigger, but it also encounters many problems due to trust, intrinsic in 
Vietnamese traditional culture, and shopping habits. Therefore, in the context of growing e-commerce market in Vietnam, it is necessary to examine the governance factors leading to sustainable performance of e-commerce businesses.

The Pareto principle, also named the 80:20 rule, states that 20 percent of customers contribute 80 percent of profits. It implies that the loyalty of the customer relationship management is a crucial factor for the sustainable performance of the B2C type of online shopping mall. The sustainable performance of web-business services should not be based on simple, instantaneous intentions in the short term, but on reuse intentions based on long term relationships [5]. Therefore, the sustainable success of an EC platform, or an e-intermediary, can be measured by the level of customer loyalty. The purpose of this research is to examine the key governance factors making an EC platform (e-intermediary) sustainably successful in a growing e-commerce industry. For this purpose, we want to examine the following three questions, based on the survey case of Lazada, a leading Vietnamese online shopping mall:

- Whether web-service quality has a positive influence on customer loyalty?

- Whether trust has a positive influence on customer loyalty and at to what extent?

- Whether trust plays a critical mediating role between web service quality and customer loyalty?

The EC platform operates as an intermediary to build the bridge between vendors and consumers. That means in an electronic platform, both sellers and buyers are the clients of the intermediary. However, it should be noted that in this research, we focus mainly on the intermediary-buyer relationship, because very little research focuses on the relationship between intermediary and seller, especially in most developing countries such as Vietnam. This paper will attempt to help these new emerging countries to develop more sustainable e-business strategies, theoretically as well as practically, with market-oriented implications and suggestions. To find out the causal effect interaction among variables from the questionnaires of the Lazada customers, SEM (Structural Equation Modeling) will be employed, with the support of the Partial Least Square (PLS) approach for examining the stability of the model and hypotheses testing. PLS is a SEM technique based on path analysis, which recently became popular for multiple-construct relationship model analysis. Especially, our paper will contribute to overcoming the relatively small sample size with the bootstrapping simulation, which will enhance statistical significance and reliability.

The rest of this paper is organized as follows: Section 1 introduces the research background, research objective, and a brief introduction of the research methodology and structure. Section 2 contains a literature review and proposes some hypotheses. In Section 2, Vietnamese the e-commerce industry overview, as well as the Lazada e-commerce platform, are presented. The previous research regarding service quality, customer loyalty, and trust are also mentioned. Section 3 contains the research model and data collection. Section 4 deals with the empirical results of the model analysis, while Section 5 concludes the study with implications, pointing out research limitations and suggesting new ideas for further research.

\section{Literature Review and Hypotheses}

\subsection{Status of Vietnam E-Commerce}

In Vietnam, online shopping malls make up only about 2.8 percent of the total retail market [4]. However, Vietnam has a rapidly increasing emerging e-commerce market in Southeast Asia, which has witnessed an impressive expansion. In 2015, revenue in Vietnam B2C e-Commerce market amounted to 4.07 billion USD. It is expected to show an annual growth rate (CAGR 2015-2020) of approximately 20 percent, expect in a market volume of 10 billion USD in 2020, driven by rapidly increasing internet penetration, a rise in personal income, competitive prices compared with offline stores, and presence of various online retail portals offering a variety of goods [4]. It also should be noted that the number of internet users in Vietnam increases rapidly year by year. There are currently 35.4 million e-commerce 
users in Vietnam, and it is predicted that 6.6 million users will be shopping online by 2021 [6]. These 42 million potential online shoppers represent 58 percent of the total population, even higher than the world average internet penetration rate of 46.64 percent [3]. The average online revenue per user currently amounts to 160 USD, according to Vietnam e-Commerce and Information Technology Agency [4].

B2C e-commerce in Vietnam supported by the potential environment could be lucrative blue ocean for both foreign and local companies. With the launch of Lotte shopping mall in October 2016, South Korean retailer Lotte expected to gain 20 percent of Vietnam e-commerce market share by 2020. Japanese retail giant Aeon also changed its position from a bystander into an aggressive player with the inauguration of its new B2C website, AeonEshop, in January 2017. Besides, some local e-commerce platforms like Sendo, Tiki, and Adayroi have positioned themselves in their home market as well. Based on the global leading model such as Amazon and Alibaba, Lazada was launched in Vietnam in 2012 and became a leading B2C e-marketplace. According to the results of a survey conducted by Asia Plus Incorporation, Lazada is the most frequently used shopping site in Vietnam with 24 percent of advocating respondents, as shown in Figure 1. Nonetheless, Lazada are confronted with tough competition by both local and foreign players. Although Lazada is a leading Vietnam e-commerce player with high market share, there is still a high risk of changing position happening in the next coming years.

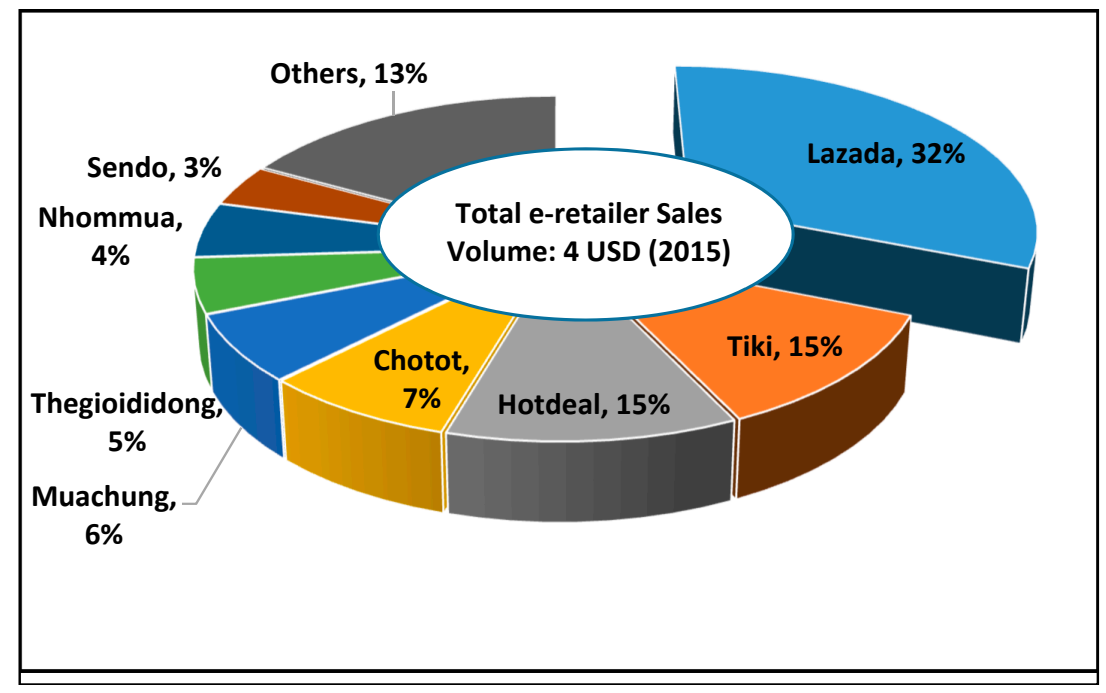

Figure 1. Vietnamese online market share. Source: Asia Plus Inc. (Tokyo, Japan), Vietnam EC Market Survey [7].

Lazada Group began as a privately owned German e-commerce company founded by Rocket Internet with its business in Indonesia, Malaysia, the Philippines, Singapore, and Thailand in 2011. In 2013, it started running e-marketplace model, allowing retailers to sell their products through Lazada's platform. The e-platform accounted for 65 percent of its sales by the end of 2014. As of April 2016, Alibaba Group bought controlling stake in Lazada under a deal worth approximately one billion dollars in order to support Alibaba's expansion plans in Southeast Asia [8]. Lazada launched Vietnam online shopping mall in 2012, reaching the leading position among 10 highest revenue e-commerce websites after three years, as shown in the Figure 1. As a B2C e-marketplace with approximately 14,000 brands and over 40,000 products in many categories, Lazada has gained the highest brand awareness in recent years. According to DI Marketing, the market share of Lazada in the Vietnamese market rose from 24 percent in 2015 to 36 percent in 2016, and it continued to be the market leader in 2017 [9].

Lazada has become an e-commerce pioneer in Vietnam by offering a fast, secure, and convenient online shopping experience. Shortly after establishment, Lazada has introduced mobile application 
helping mobile-users easily to get access and unlimited-shopping on the go. Lazada Vietnam has reached a milestone of more than 110 million visits to its desktop and mobile sites in the second quarter of 2015, as shown in the Figure 2. This achievement reflects customer preference in shopping on Lazada, affirming its leading position in Vietnam e-commerce industry [10].

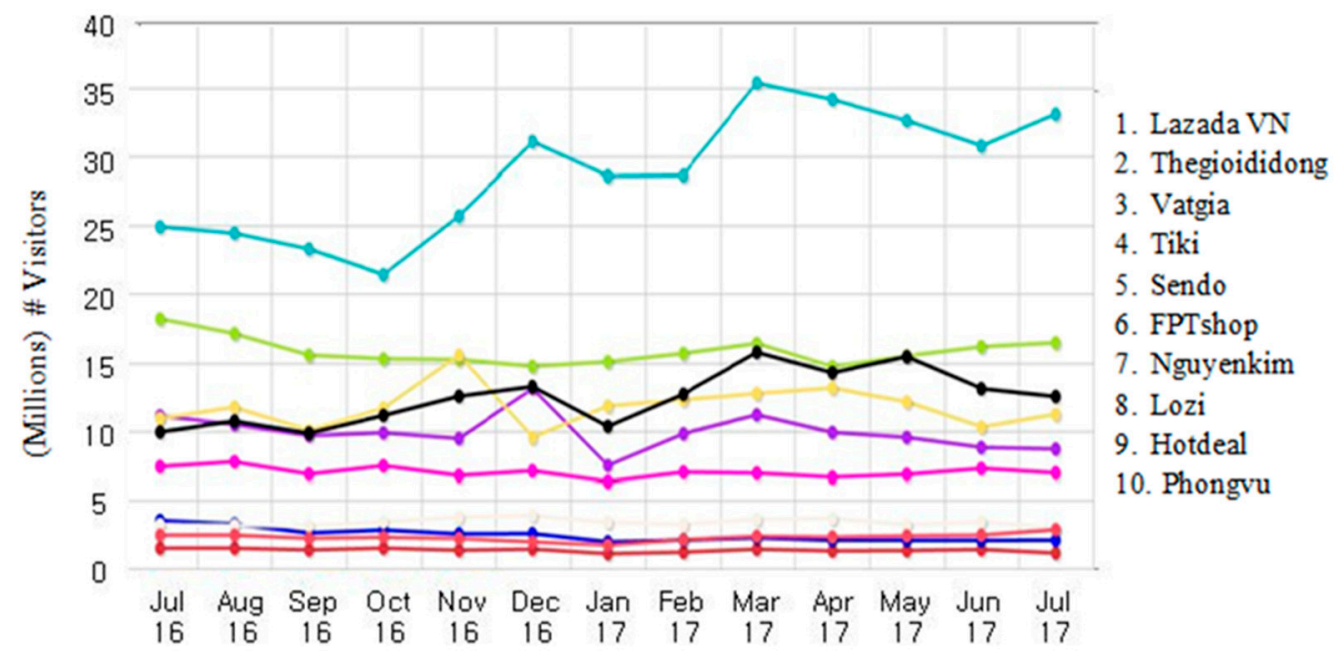

Figure 2. Monthly B2C web traffic in Vietnam. Source: SimilarWeb Ltd. (New York, NY, USA) (www.similarweb.com/website/lazada.vn).

Figure 2 shows that Vietnam B2C e-marketplace was led by the most popular Lazada shopping site, continuously from July 2016 to July 2017, indicating that Lazada gains most of awareness of consumers. Some people might not think of e-marketplace such as Amazon, Alibaba, and Lazada as sales intermediaries, but they are intermediaries with effective connection between sellers and buyers, in a structured and secured environment. In a simple way, intermediary can be defined as a third party that offers intermediation services between two parties. Common to all intermediaries is that they mediate between suppliers (or sellers) and consumers (or buyers) of goods and service [11]. Since the paradigm of the web based service business is based on the "value creation based on the network management" [2] (p. 57), it is crucial for an intermediary in new digital era to generate trust and coordinate the roles of different divisions as a metamediary [12].

Unfortunately, for all online retailers to gain customer trust is the biggest challenge. This is true especially in Vietnam where the consumer is traditionally not acquainted with online shopping. Recently, research analyzed how consumers are complaining about online shopping, with more than 30,000 reviews at 5000 e-commerce websites in Vietnam, Malaysia, Singapore, Indonesia, and the Philippines [7]. As shown in the Figure 3, the research shows that Vietnamese consumers have the lowest reliability when it comes to online shopping. Vietnamese end-users complain about fakes more than any other country in the region. They usually have common queries regarding the product's origin (or product authorization) compared with other Southeast Asian web consumers who only ask about the purchase process. Most of Vietnamese consumers prefer chatting directly with suppliers to acquire more detail about the product. The lack of trustworthiness in e-commerce makes customers unwilling to spend money on online shopping [13]. The great number of sales cancellations implies that products are of a lower quality than what they expected before ordering. Vietnam shows the highest rate of order cancellation, with 30 percent of products being rejected due to product failure. As shown in the figure, product quality concern is the most common reason, accounting for 57 percent of respondents, whilst the second-ranked reason relates to security concern at 25 percent. In reality, a large number of Vietnamese people prefer visiting an offline store to have a real visual-and-touching interaction before making a purchase decision. The concern about low-quality products and leak of personal information makes internet users hesitant to participate in e-commerce. Meanwhile, 
local businesses have not developed enough trust for Vietnamese consumers to change their purchasing habits, which are traditionally not familiar with online shopping. Building trust with local consumers means understanding their culture. A major hindrance of brand building in several South East Asian markets is a cash-driven culture. Vietnamese chose COD (cash on delivery) as their first choice for e-commerce due to the lack of e-trust [9]. Alipay in Chinese market is the most successful tool to have overcome this kind of cash-based transaction [14].

Lazada has overcome this lack of trust by providing risk-free shopping environment with a broad range of secured payment options (including cash on delivery-the key to getting new customers on board) and 30-day return policy for customers. Besides, they also assure the customers about the qualifications of the sellers through strictly examining and assessing the suppliers. The company has set up a team specialized in sorting and examining products, especially of large brands, to ensure that the products are genuine. In some circumstances, Lazada asks for brand-certified authorization from suppliers to prevent counterfeit goods. In addition, buyers are encouraged to give feedback if they are suspicious about the origin of the product. Lazada is extremely strict and severely punishes on the counterfeit products, removing the vendor from the site if infringements occur several times. Lazada launched a certification program that labels a 'trust-badge' to all products coming from certified sellers. Now, we want to examine these efforts of Lazada to give new hope to the Vietnamese e-commerce market via sustainable governance factors. In order to analyze these governance factors, we shall set up the hypotheses from the literature in the following section.

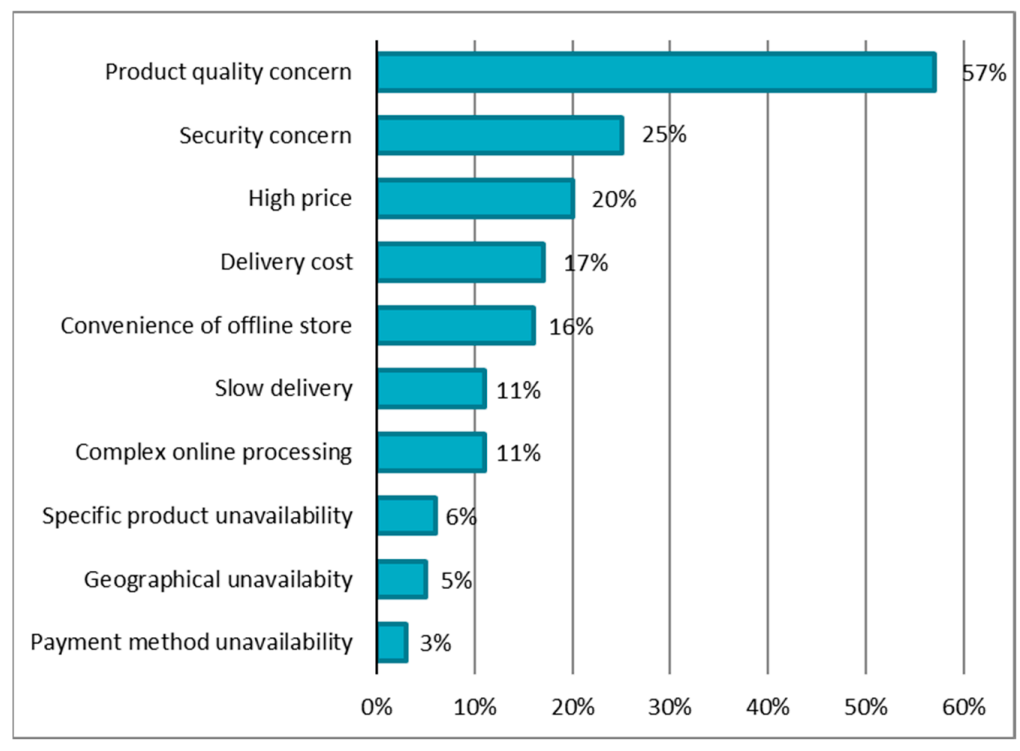

Figure 3. Reasons for not using e-commerce among Vietnamese consumers. Source: Asia Plus Inc. (2016). Vietnam E-commerce Market Survey [13].

\subsection{Customer Loyalty}

Customer loyalty is defined as a commitment to buy or patronize a preferred product or service consistently, indicating repetitive same brand purchasing, regardless of situational influences and marketing efforts to trigger behavior switching [15]. Srinivasan and Anderson extended a more specific definition of customer loyalty in online shopping of e-loyalty: favorable attitudes of customer towards an electronic business, causing repetitive purchasing behavior [16]. In an increasingly competitive environment, the loyalty of consumers could be one of the main factors to strengthen the market competitiveness and to reinforce sustainable competitive advantage, because appealing to new customers is remarkably more costly than retaining existing customers [17].

Customer loyalty enlarges future sales volumes and exponentially increases sales through viral marketing. Relationship management is central to the creation of value for the network manager. 
Web marketing should emphasize relationship building, relationship management, and value creation from relationships [18].

The success of an e-commerce company depends much on maintaining customer loyalty [19]. As a consequence, it is crucial for e-commerce companies to manage a loyal customer base, because long-term customer relationships are not only a current main profit contributor but also have a high potential to enlarge the sales volume in the future. For these reasons, the sustainable success of an e-commerce platform for intermediaries can be symbolized by the level of customer loyalty. This customer loyalty may come from the governance factors of service quality. We will explain this causal relationship in the following section.

\subsection{Hypotheses on Service Quality and E-Trust}

E-commerce platform is a primary basis for multi-channel transactions in which product or service information is provided by multiple third-parties and transactions are processed by the platform operator. Because of the role in providing product and service information, EC platform operating company can also be considered as a service provider. Therefore, an e-platform consists of the diverse characteristics as a service provider and thus can be evaluated through its service quality. Service quality (SQ) is the comparison between perceived expectations of a service and perceived performance [20]. Parasuraman et al. (1988) proposed five dimensions of this gap of service quality with the SERVQUAL model: Responsiveness, Assurance, Tangibles, Empathy, and Reliability [21]. However, SERVQUAL focuses on the traditional buyer-seller interaction, but does not embrace the interaction between customer and website, which is one unique character of e-commerce service quality. Therefore, Kim et al. (2012) extended this model added by information quality [22]. In online shopping environment, service quality must get assisted with the consumer's purchasing by providing security and accessibility, in addition to speed and other convenience features, creating the importance of the information quality [23]. Information quality is perceived as the assurance value of outputs produced by a website [24].

Ribbink (2004) adopted this assurance and responsiveness from SERVQUAL model in their research [25]. Chiu et al. (2009) chose responsiveness and security as two among seven determinants of repurchase intention [26]. Yang et al. (2009) specified that transaction cost saving (convenience), reliability, responsiveness, and assurance are some of main factors in online game service [27]. Anderson and Swaminathan (2011) suggested interaction, commitment (responsiveness), and assortment (usefulness) as three among eight determinants that have an effect on loyalty in e-market [28]. Kim et al. (2012) mentioned security, variety (usefulness), responsiveness, and receptiveness in their research about internet shopping value and customer repurchase intention [22]. Choi \& Sun (2015) chose a set of five dimensions: usefulness, convenience, security, responsiveness, and economy as main quality factors of third online payment service [14]. All these arguments show the common factors of e-service quality with usefulness, convenience, security, responsiveness, and assurance. The last common factor of assurance is especially important in that the Vietnamese cultural background always emphasized the risk-averse attitude in commercial transactions, as shown in the Figure 3. Based on these arguments, we can draw the following hypotheses for the causal relationship between the web service quality and its resulting customer loyalty. All these hypotheses on the five characteristics of web business service platforms and customer loyalty (H1-H5) constitute the research direct model, as shown in Figure 4.

Hypothesis 1 (H1). Usefulness of e-commerce platform has a positive effect on customer loyalty.

Hypothesis 2 (H2). Convenience of e-commerce platform has a positive effect on customer loyalty.

Hypothesis 3 (H3). Security of e-commerce platform has a positive effect on customer loyalty.

Hypothesis 4 (H4). Responsiveness of e-commerce platform has a positive effect on customer loyalty. 
Hypothesis 5 (H5). Assurance of e-commerce platform has a positive effect on customer loyalty.

In the field of e-commerce, the terms and conditions of e-trust are mostly utilized in marketing and information system analyses as well [14]. Due to the risk of purchasing a product online from an unfamiliar vendor, e-trust remains a critical issue in an electronic transaction [29]. Hong and Cho (2011) stipulated that one of the main roles of intermediary in e-marketplace is to convince and appeal consumers into a risk-free e-commerce environment [29]. As Pennanen et al. argued, consumer trust and e-trust could be interchangeably used in the literature [30]. In most of the literature, trust in traditional marketing implies the integrity and reliability of the product, while e-trust emphasizes the safe, riskless transactions available in the online market environment [30]. Based on these arguments, we will use e-trust in this paper with the interchangeable characteristics of traditional trust. Choi and Jin used the initial trust as the concept of e-trust, and on-going trust as the traditional concept of trust [31].

The elements of service quality are expected to have an impact on trust directly. Because there is no face-to-face interaction on the e-commerce platform, the web business service quality becomes much more important as the mediator between the service quality and customer loyalty [14]. Obviously, a first impression of good e-service quality is likely to enhance reliability, which means that higher service quality results in a higher level of trust. Previous research showed the strong relationship between the determinants of service quality and the level of trust [24-27,31]. Based on these arguments, we propose the following hypotheses on the trust.

Hypothesis 6 (H6). Usefulness of e-commerce platform has a positive effect on trust.

Hypothesis 7 (H7). Convenience of e-commerce platform has a positive effect on trust.

Hypothesis 8 (H8). Security of e-commerce platform has a positive effect on trust.

Hypothesis 9 (H9). Responsiveness of e-commerce platform has a positive effect on trust.

Hypothesis 10 (H10). Assurance of e-commerce platform has a positive effect on trust.

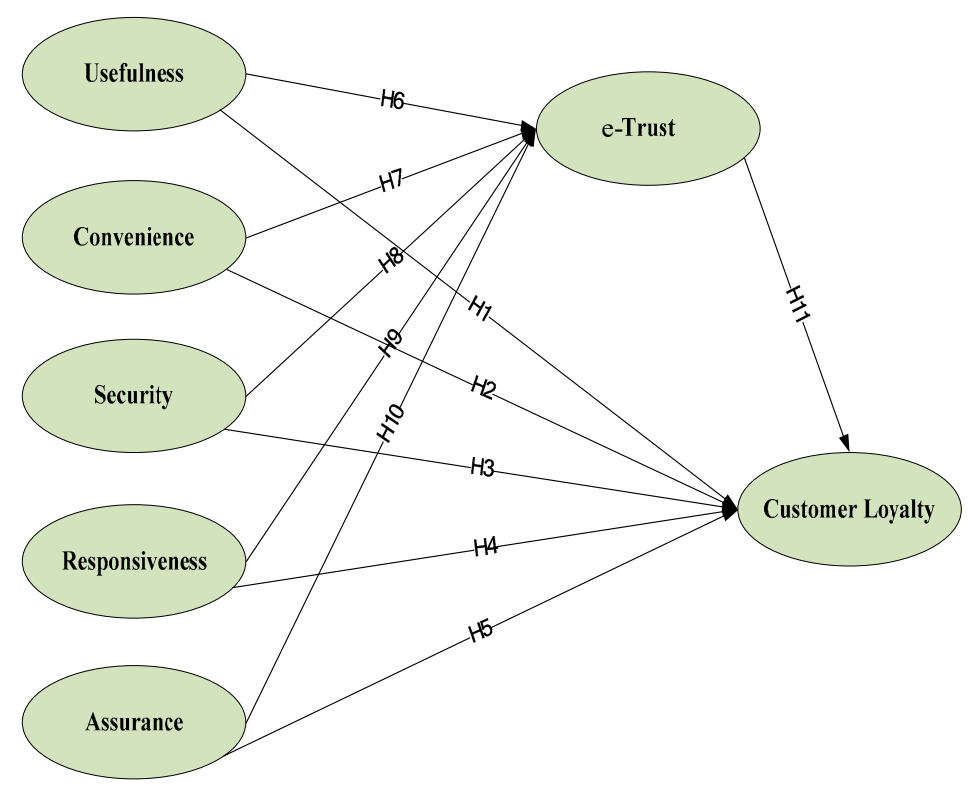

(a)

Figure 4. Cont. 


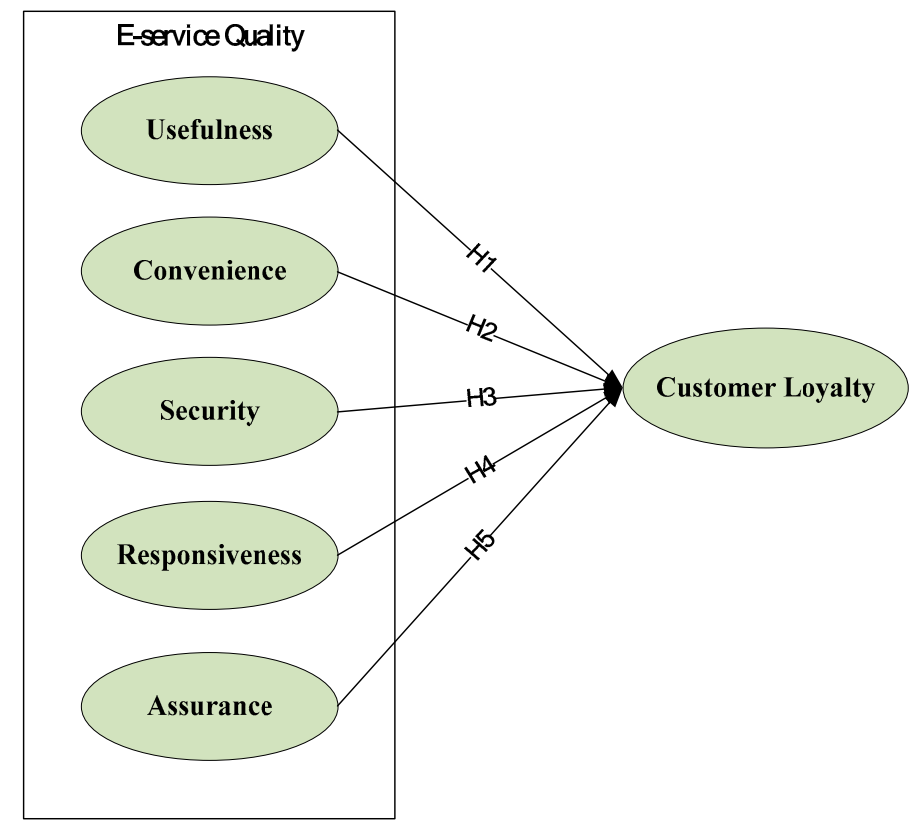

(b)

Figure 4. (a) Indirect model with trust as a moderator, (b) research direct model between service quality and customer loyalty.

E-Trust is a key to building customer loyalty and maintaining continuous relationship with the consumers. There is a general consensus among the evidence supporting the impact of trust on customer loyalty $[24,28,31]$, resulting in the following hypothesis.

Hypothesis 11 (H11). Trust has a positive effect on customer loyalty.

With the appearance of trust as a mediator, our model can be considered as the indirect model. As shown in the Figure 5, the propositions of trust in the framework show its role as a mediator of the path between service quality and customer loyalty. In order to test all these hypotheses and verify the role of mediator, we will explain the method more in detail and results of analysis in the following section.

\section{Research Methodology and Data Collection}

\subsection{Data Collection and Methodology}

This research follows the quantitative approach to describe and test relationships among variables: web service quality including usefulness (USE), convenience (CON), security (SEC), responsiveness (RES), assurance (ASR), trust (TRUST), and customer loyalty (LOY). For the stepwise causal relationship, Partial Least Squares (PLS) model is applied to examine stability of the model and to test hypotheses. PLS is a structural equation modeling (SEM) technique based on path analysis and regression analysis, and recently get popularity increasingly for multiple-construct relationship analysis. Although there are still some cautions for using PLS, several advantages to choose PLS as a statistical approach for structural equation modeling can be summarized [31]. First, PLS path modeling analyzes well a small sample and avoids problems from inappropriate sample size. Second, PLS can analyze complex structural equation models with many constructs and variables more effectively. Third, PLS requires fewer assumptions regarding normal variable distribution and error terms. Forth, PLS simultaneously handles both reflective and formative indicators. Fifth, PLS better suits theory development than theory testing and is especially useful for prediction. Sixth, and last, PLS overcomes multi-collinear issue. 
From all these reasons, we choose PLS as the analytical method in this research. However, since PLS does not test significance, a re-sampling approach is used for significance testing [32]. To overcome this issue and to simulate a random sample size, the bootstrapping method was applied. Bootstrapping treats the observed samples as if they represent the population [31]. With the bootstrapping simulation, corresponding sample could be used for conducting statistical examination and testing hypotheses. In this research, we set the number of simulated sample at 2000 to achieve stability of parameter estimation [33]. PLS analysis was performed by Smart PLS 2.0 software (Berlin, Germany). Referring to the previous studies [24,25,31], the PLS analysis will be executed sequentially as the following order:

- Reliability test of measurement model

- Convergent and discriminant validity test of measurement model

- Goodness-of-fit of the research model

- Hypotheses testing of direct and indirect model

- Mediation effect testing

A survey was used to collect the original data. The study was conducted in the big cities such as Hanoi and Hochimin city in Vietnam, where the majority of urban residents have access to the internet and high demand for online shopping. First, eight multi-choice questions in the questionnaire are shown to collect basic personal information, such as gender, age, education level, online shopping frequency, etc. The main content of the questionnaire comprises thirty questions based on 5-point Likert scale, ranging from 1 (strongly disagree) to 5 (strongly agree). Quantifiable data were obtained through a structured questionnaire of seven categories: usefulness (5 questions), convenience (4 questions), security (4 questions), responsiveness (5 questions), assurance (4 questions), trust (4 questions), and customer loyalty (5 questions).

The survey was conducted from 16 October to 6 November 2017. The questionnaires were randomly dispatched to e-commerce users via e-mail and messenger. Except for inappropriate responses (including responses from those with no shopping experience on Lazada), 231 out of 265 unique and usable responses were collected, with an acceptance rate of 87.17 percent. The survey sample shows the majority of e-commerce users are in the age range of 18-30; university graduates and post-graduates account for over 90 percent of respondents, implying that millennial generation with good educational background becomes much accustomed to e-commerce sites. Shopping frequency of 1 or 2 times per month accounts for approximately 46 percent, reflecting a reasonable familiarity with online shopping. Table 1 shows the details of the characteristics of the respondents.

Table 1. Descriptive statistics.

\begin{tabular}{ccc}
\hline Characteristics & Items & Percentage \\
\hline \multirow{2}{*}{ Gender } & Male & $55 \%$ \\
& Female & $45 \%$ \\
\hline \multirow{2}{*}{ Age } & Under 18 & $0.4 \%$ \\
& $18-30$ & $87.4 \%$ \\
& $30-45$ & $11.7 \%$ \\
& Over 45 & $0.4 \%$ \\
\hline \multirow{2}{*}{ Education level } & Under high school & $0.4 \%$ \\
& High school graduate & $2.6 \%$ \\
& College & $5.2 \%$ \\
& University graduate & $71.0 \%$ \\
& Post-graduate & $19.9 \%$ \\
& Others & $0.9 \%$ \\
\hline Shopping & Rarely & $30.7 \%$ \\
frequency & $1-2$ times/month & $45.9 \%$ \\
& 3-4 times/month & $13.0 \%$ \\
& Over 5 times/month & $10.4 \%$ \\
\hline
\end{tabular}




\subsection{Reliability Test, and Convergent and Discriminant Validity Test}

In PLS, the indicator of latent construct relationship is referred as the outer model or measurement model. Factor loading and reliability test results of these construct items are important to represent the proxy variables with different but consistent questions. Since the traditional Cronbach's $\alpha$ test tends to give an underestimation of the reliability of latent variables in PLS, and thus, a more appropriate measure, so called Composite reliability (CR) test is applied [34]. This composite reliability test can be interpreted in the same way as Cronbach's $\alpha$. If composite reliability values of all constructs are higher than 0.7, this suggests that the constructs are reliable and acceptable [34]. In addition, Hair et al. (2010) also suggest a cut-off value at 0.5 as critical requirement for reliability [35]. As shown in Table 2, all the questions for the variables are accepted by this criteria as well.

Table 2. Reliability test results.

\begin{tabular}{|c|c|c|c|c|}
\hline Construct & Measurement Items & $\begin{array}{l}\text { Factor Loading/Coefficient } \\
\quad(t \text {-Value })(>0.5)\end{array}$ & $\begin{array}{c}\text { Composite } \\
\text { Reliability }(>0.7)\end{array}$ & $\operatorname{AVE}(>0.5)$ \\
\hline \multirow{5}{*}{ Usefulness (USE) } & Use1 & $0.783^{* * *}$ & \multirow{5}{*}{0.868} & \multirow{5}{*}{0.568} \\
\hline & Use2 & $0.719^{* * *}$ & & \\
\hline & Use3 & $0.757^{* * *}$ & & \\
\hline & Use4 & $0.802^{* * *}$ & & \\
\hline & Use5 & $0.704^{* * *}$ & & \\
\hline \multirow{4}{*}{ Convenience (CON) } & Con1 & $0.843^{* * *}$ & \multirow{4}{*}{0.863} & \multirow{4}{*}{0.613} \\
\hline & Con2 & $0.747^{* * *}$ & & \\
\hline & Con3 & $0.719^{* * *}$ & & \\
\hline & Con4 & $0.817^{* * *}$ & & \\
\hline \multirow{4}{*}{ Security (SEC) } & Sec1 & $0.764^{* * *}$ & \multirow{4}{*}{0.912} & \multirow{4}{*}{0.721} \\
\hline & Sec2 & $0.874^{* * *}$ & & \\
\hline & Sec3 & $0.884^{* * *}$ & & \\
\hline & Sec4 & $0.869^{* * *}$ & & \\
\hline \multirow{5}{*}{ Responsiveness (RES) } & Res1 & $0.856^{* * *}$ & \multirow{5}{*}{0.923} & \multirow{5}{*}{0.707} \\
\hline & Res2 & $0.746^{* * *}$ & & \\
\hline & Res3 & $0.870 * * *$ & & \\
\hline & Res4 & $0.853^{* * *}$ & & \\
\hline & Res5 & $0.871^{* * *}$ & & \\
\hline \multirow{4}{*}{ Assurance (ASR) } & Asr1 & $0.743 * * *$ & \multirow{4}{*}{0.899} & \multirow{4}{*}{0.693} \\
\hline & Asr2 & $0.859 * * *$ & & \\
\hline & Asr3 & $0.859 * * *$ & & \\
\hline & Asr4 & $0.863 * * *$ & & \\
\hline \multirow{4}{*}{ e-Trust (TRUST) } & Trust1 & $0.882 * * *$ & \multirow{4}{*}{0.928} & \multirow{4}{*}{0.764} \\
\hline & Trust2 & $0.873^{* * *}$ & & \\
\hline & Trust3 & $0.916^{* * *}$ & & \\
\hline & Trust4 & $0.822^{* * *}$ & & \\
\hline \multirow{4}{*}{ Customer loyalty (LOY) } & Loy1 & $0.876^{* * *}$ & \multirow{4}{*}{0.947} & \multirow{4}{*}{0.817} \\
\hline & Loy2 & $0.924^{* * *}$ & & \\
\hline & Loy3 & $0.903^{* * *}$ & & \\
\hline & Loy4 & $0.911^{* * *}$ & & \\
\hline
\end{tabular}

Two tests including convergent validity test and discriminant validity test were performed with a view to validating the construct validity. According to Fornell and Larcker [34], the constructs display convergent validity if:

- $\quad$ factor loads of indicators are greater than 0.5;

- reliability value is greater than 0.7;

- the average variance extracted (AVE) is greater than 0.5.

As shown in Table 3, all of the constructs satisfy these criteria, exhibiting favorable convergent validity.

Discriminant validity is used to examine the cross loading differences among different constructs. According to Campbell and Fiske (1959), construct validity tests the extent to which data provide discriminate validity [36]. Discriminant validity is adequate once the correlation of one construct 
with its indicators exceeds the correlation of that construct with other variables [37]. Table 3 shows us the result of the correlation matrix, indicating whether the square root of AVE is greater than the correlation coefficient of the constructs. All of cross loadings were over 0.6. Indications of both Tables 2 and 3 show that the constructs achieve discriminant validity.

Table 3. Correlation matrix.

\begin{tabular}{cccccccc}
\hline Variables & USE & CON & SEC & RES & ASR & TRUST & LOY \\
\hline USE & $\mathbf{0 . 7 5 3 0 ^ { \mathbf { a } }}$ & & & & & & \\
CON & 0.7129 & $\mathbf{0 . 7 8 1 5} \mathbf{a}$ & & & & & \\
SEC & 0.5528 & 0.5925 & $\mathbf{0 . 8 4 7 7} \mathbf{a}$ & & & & \\
RES & 0.5618 & 0.5952 & 0.6662 & $\mathbf{0 . 8 3 9 2} \mathbf{a}$ & & & \\
ASR & 0.6492 & 0.6764 & 0.6435 & 0.6548 & $\mathbf{0 . 8 3 1 0} \mathbf{a}^{\mathbf{a}}$ & & \\
TRUST & 0.6330 & 0.6202 & 0.6713 & 0.7192 & 0.7619 & $\mathbf{0 . 8 7 3 2} \mathbf{a}$ & \\
LOY & 0.6477 & 0.6654 & 0.6151 & 0.6878 & 0.7090 & 0.8079 & $\mathbf{0 . 9 0 3 5}^{\mathbf{a}}$ \\
\hline
\end{tabular}

USE = Usefulness; CON = Convenience; SEC = Security; RES = Responsiveness; ASR = Assurance; LOY = Customer Loyalty. The bolded numbers ${ }^{a}$ on the diagonal are the square root of AVE.

The goodness-of-fit test examines how well it fits a set of variables as a model. Goodness-of-fit is measured by the discrepancy between observed values and expected values in questionnaire. In general, a model fits the data better if the differences between observed values and predicted ones are small and unbiased. R-squared is a statistical measure of how close the data are to the fitted regression line. It is also known as the coefficient of determination, or the coefficient of multiple determinations for multiple regressions. In our model, trust and customer loyalty have R-squared values of 0.69 and 0.71 respectively, implying that the independent variables explain an estimated 69 percent and 71 percent of the variation in Trust and Customer loyalty. Therefore, based on the test, the variables fit reasonably well to the model overall.

\section{Research Methodology and Empirical Results}

\subsection{Structural Model Result}

\subsubsection{Direct Model Results}

In PLS, the path structures between constructs constitute the inner model (structural model). Inner model includes direct model and indirect model. Direct model just shows the simple causality between the service quality and its performance by customer loyalty. To find out this direct causality, Table 4 summarizes the path significance, coefficient $\mathrm{t}$-values and hypotheses testing results. The visualized description is illustrated in the Figure 5.

Table 4. Hypotheses testing results of direct model.

\begin{tabular}{ccccc}
\hline Hypotheses & Path & Path Coefficient & $\boldsymbol{t}$-Value & Result \\
\hline H1 & USE $\rightarrow$ LOY & $0.165^{*}$ & 2.310 & Accepted \\
H2 & CON $\rightarrow$ LOY & $0.159^{*}$ & 2.395 & Accepted \\
H3 & SEC $\rightarrow$ LOY & 0.076 & 1.308 & Rejected \\
H4 & RES $\rightarrow$ LOY & $0.279^{* * *}$ & 4.383 & Accepted \\
H5 & ASR $\rightarrow$ LOY & $0.263^{* * *}$ & 4.213 & Accepted \\
\hline
\end{tabular}

USE = Usefulness; CON = Convenience; SEC = Security; RES = Responsiveness; ASR = Assurance; LOY = Customer Loyalty * $p$-value $<0.05 ;{ }^{* * *} p$-value $<0.001$.

As shown in Table 4, the direct path of SEC to LOY (security to loyalty) failed to achieve significance, with path coefficient of 0.076 ( $p$-value $>0.05$ ), implying H3 was rejected. It can be inferred that security has no significant influence on customer loyalty. E-commerce users seem to give a fairly low assessment on security factor of Lazada website. Despite the effort of Lazada in offering security protection, customers do not display strong loyalty toward the platform. As shown 
in Figure 3, security concern is the second critical reason why Vietnamese consumers are reluctant to purchase online, and thus Lazada desperately needs the modulator for this security to be effective in the long term.

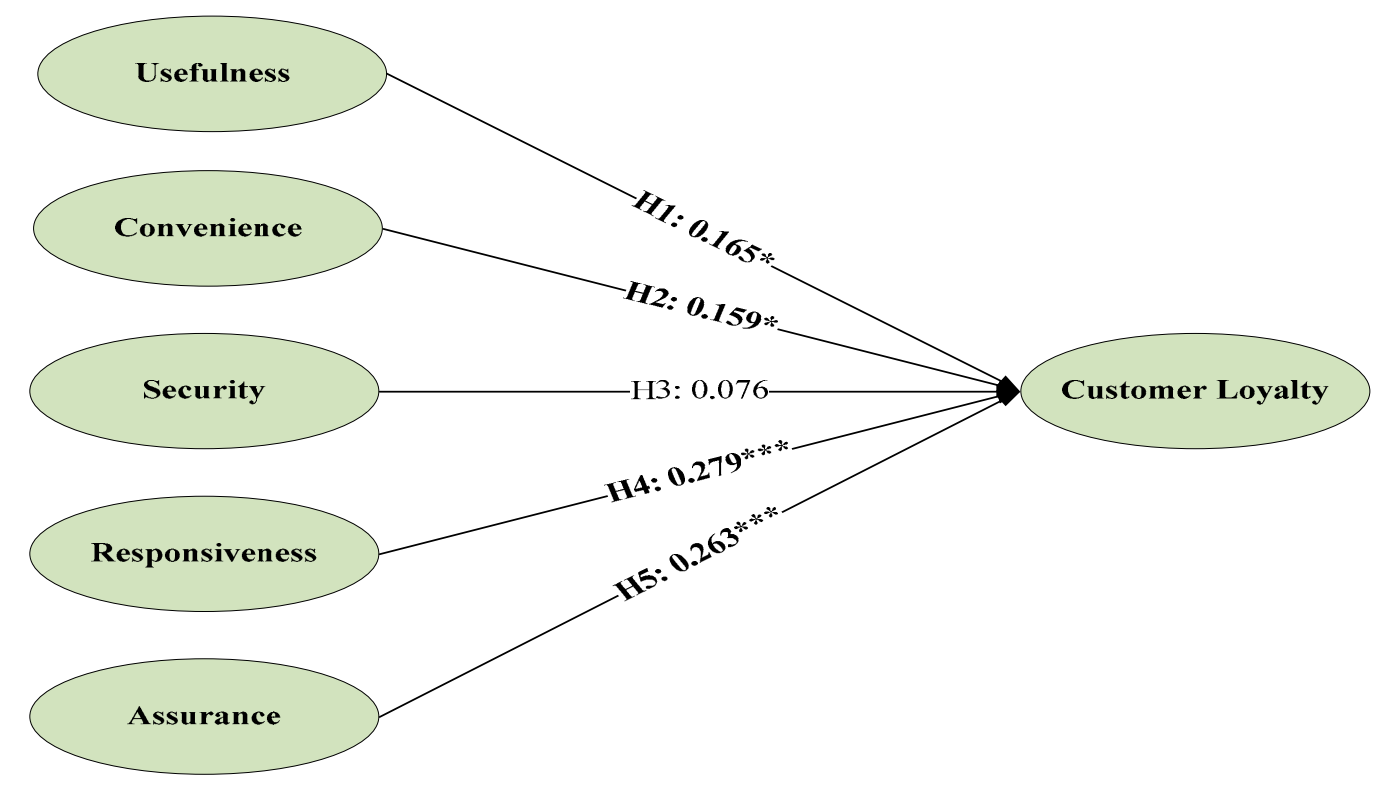

Figure 5. Results of the direct model. Note: ${ }^{*} p$-value $<0.05 ; * * *$-value $<0.001$.

In direct model, apart from H3, analysis results supported for H1, H2, H4, H5: usefulness, convenience, responsiveness, and assurance of the web service quality have a significant influence on the customer loyalty. Since four among five characteristics of e-commerce platform have the direct significant impact on customer loyalty, Lazada should consider these four website characteristics as the strategic factors to enhance the customer loyalty. Especially, responsibility and assurance (H4 and H5) should be paid more attention due to its bigger coefficients, indicating the stronger influence on the customer loyalty ( 0.279 and 0.263 , respectively). If these two key factors are emphasized more, more customers are likely to gladly participate in the long-term transaction.

\subsubsection{Indirect Model Results with E-Trust as the Modulator}

Now, based on the direct model, the role of e-trust shall be analyzed in indirect model. To find out the change of all the web service quality variables with the trust in the model, the results of the indirect model are shown in Table 5 and Figure 6, with the path significance, coefficient $t$-values, and hypotheses testing results. In the indirect model, except for $\mathrm{H} 7$ (convenience to e-trust), all the other five hypotheses (H6, H8, H9, H10, and H11) were supported at the 95 percent significance level. Usefulness, security, responsiveness, and assurance have a significantly positive influence on trust, while e-trust has a significantly positive influence on customer loyalty.

Among those favorable paths, Responsiveness (H9) and Assurance (H10) showed a stronger effect on the e-trust. Since the moderator, trust, also showed strong effect on the customer loyalty, we want to examine the role of moderator in the model in more detail. 


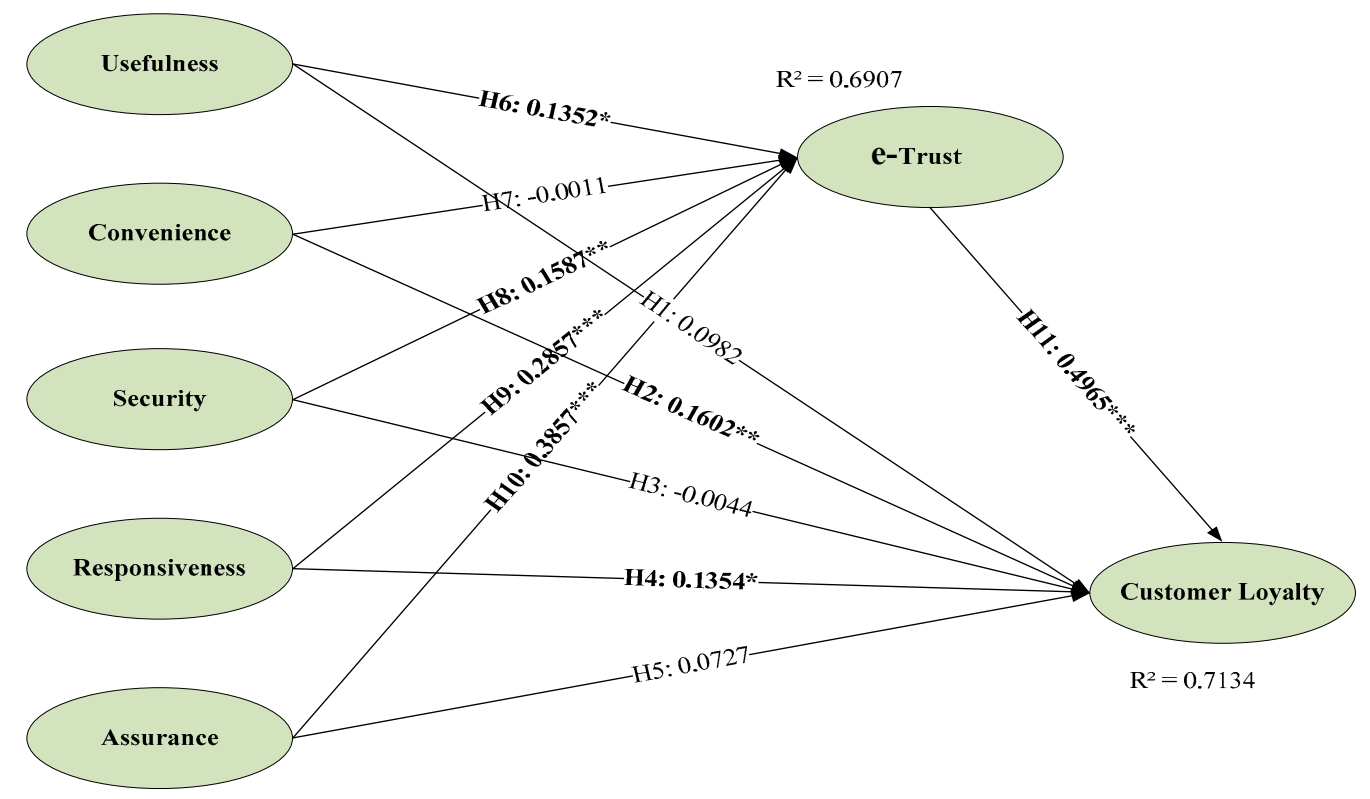

Figure 6. Results of the indirect model. Note: ${ }^{*} p$-value $<0.05 ;{ }^{* *} p$-value $<0.01 ;{ }^{* *} p$-value $<0.001$.

Table 5. Hypotheses testing results of indirect model.

\begin{tabular}{ccccc}
\hline Hypotheses & Path & Path Coefficient & $\boldsymbol{t}$-Value & Result \\
\hline H1 & USE $\rightarrow$ LOY & 0.0982 & 1.699 & Rejected \\
H2 & CON $\rightarrow$ LOY & $0.1602^{* *}$ & 2.817 & Accepted \\
H3 & SEC $\rightarrow$ LOY & -0.0044 & 0.089 & Rejected \\
H4 & RES $\rightarrow$ LOY & $0.1354^{*}$ & 2.272 & Accepted \\
H5 & ASR $\rightarrow$ LOY & 0.0727 & 1.156 & Rejected \\
H6 & USE $\rightarrow$ TRUST & $0.1352^{*}$ & 2.072 & Accepted \\
H7 & CON $\rightarrow$ TRUST & -0.0011 & 0.018 & Rejected \\
H8 & SEC $\rightarrow$ TRUST & $0.1587^{* *}$ & 2.589 & Accepted \\
H9 & RES $\rightarrow$ TRUST & $0.2857^{* * *}$ & 4.127 & Accepted \\
H10 & ASR $\rightarrow$ TRUST & $0.3857^{* * *}$ & 6.306 & Accepted \\
H11 & TRUST $\rightarrow$ LOY & $0.4965^{* * *}$ & 6.597 & Accepted \\
\hline
\end{tabular}

USE = Usefulness $;$ CON = Convenience; SEC = Security; RES = Responsiveness; ASR = Assurance; LOY = Customer Loyalty * $p$-value $<0.05 ;{ }^{* *} p$-value $<0.01 ;{ }^{* * *} p$-value $<0.001$.

\subsection{Moderating Effect of the E-Trust}

After testing hypotheses of direct and indirect model, then mediation effect test can be performed. According to Baron and Kenny (1986), mediation can be said to occur if following conditions are satisfied [38]:

- Independent constructs significantly affect the dependent construct in direct model;

- Independent constructs significantly affect the mediator;

- The mediator has a significant unique effect on the dependent construct;

- The effect of independent constructs on the dependent construct shrinks upon the addition of mediator to the model.

To examine these criteria, a series of statistical-based methods have been introduced. In this research, three versions of Sobel test (Sobel test, Aroian test, and Goodman test) were taken to analyze the mediation effect. The purpose of these tests is to determine whether TRUST carries the influence of service quality (USE, CON, SEC, RES, ASR) to the customer loyalty (LOY). In order to test the mediation effect by Sobel tests, however, large sample sizes are required. Since Sobel tests evaluate a given sample under the normal distribution, problems may exist with the small sample size [39]. 
For the appropriate Sobel test, this research employed bootstrapping method to create a simulated sample size of 2000. Thus, the simulated sample totally satisfied the requirement of Sobel tests [40], and the results of the tests are presented in the following Table 6.

Table 6. Mediation effects testing.

\begin{tabular}{|c|c|c|c|c|c|}
\hline \multirow{2}{*}{\multicolumn{2}{|c|}{$\begin{array}{l}\text { Path/Construct Relationship } \\
\text { (Role of Mediator) }\end{array}$}} & \multirow{3}{*}{$\begin{array}{c}\begin{array}{c}\text { Path Coefficient } \\
\boldsymbol{t} \text {-Value }\end{array} \\
2.072 \\
6.597\end{array}$} & \multicolumn{3}{|c|}{$z$-Value } \\
\hline & & & \multirow{2}{*}{$\begin{array}{c}\text { Sobel Test } \\
1.977^{*}\end{array}$} & \multirow{2}{*}{$\begin{array}{c}\text { Aroian Test } \\
1.960^{*}\end{array}$} & \multirow{2}{*}{$\begin{array}{c}\text { Goodman Test } \\
1.998^{*}\end{array}$} \\
\hline 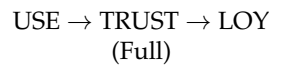 & $\begin{array}{l}\text { H6 } \\
\text { H11 }\end{array}$ & & & & \\
\hline $\mathrm{CON} \rightarrow \underset{(\text { None) }}{\text { TRUST }} \rightarrow$ LOY & $\begin{array}{l}\text { H6 } \\
\text { H11 }\end{array}$ & $\begin{array}{l}0.018 \\
6.597\end{array}$ & 0.018 & 0.018 & 0.018 \\
\hline $\begin{array}{c}\mathrm{SEC} \rightarrow \underset{\text { (Full) }}{\mathrm{TRUST}} \rightarrow \text { LOY } \\
\text { L }\end{array}$ & $\begin{array}{l}\text { H6 } \\
\text { H11 }\end{array}$ & $\begin{array}{l}2.589 \\
6.597\end{array}$ & $2.410^{*}$ & $2.386^{*}$ & $2.434^{*}$ \\
\hline $\begin{array}{l}\text { RES } \rightarrow \\
\rightarrow \text { (Partial) }\end{array}$ & $\begin{array}{l}\text { H6 } \\
\text { H11 }\end{array}$ & $\begin{array}{l}4.127 \\
6.597\end{array}$ & $3.499 * * *$ & $3.470^{* * *}$ & $3.528^{* * *}$ \\
\hline$\underset{\text { (Full) }}{\mathrm{ASR}} \rightarrow \underset{\text { TRUST }}{\mathrm{TOOY}}$ & $\begin{array}{l}\text { H6 } \\
\text { H11 }\end{array}$ & $\begin{array}{l}6.306 \\
6.597\end{array}$ & $4.558^{* * *}$ & $4.531^{* * *}$ & $4.586^{* * *}$ \\
\hline
\end{tabular}

USE = Usefulness; CON = Convenience; SEC = Security; RES = Responsiveness; ASR = Assurance; LOY = Customer Loyalty * $p$-value $<0.05 ;{ }^{* * *} p$-value $<0.001$.

MacKinnon et al. [40] suggested that the presence of a mediation effect occurs when the absolute $z$-value is greater than 1.96. According to Baron and Kenny [38], in the case that all of four above-mentioned criteria are satisfied, there may be two possibilities regarding the role of mediator in the model:

(1) If the effect of independent variable becomes minor under the appearance of mediator, then it can be stated that the effect of independent variable is "fully" mediated by the mediator;

(2) If the effect of independent variable stays strong under the appearance of mediator, then mediator's role is "partially" mediated between independent and dependent variables.

It can be proposed from (1) and (2) that, in the case of mediator's appearance supported by the results of three tests in Table 6, there are also two possibilities for the role of mediator: "full" (or "completed") mediation and "partial" mediation.

As shown in Table 6, since no significant relationship between convenience and trust is found, the role of mediator in path CON $\rightarrow$ TRUST $\rightarrow$ LOY does not exist (no-mediation). Apart from this factor, all the other $\mathrm{z}$-values of statistics are greater than 1.96, supporting the presence of mediator in four remaining paths. The role of mediator in these paths is listed in Table 6. From the table, the effect of usefulness, security, and assurance on the customer loyalty is "fully" mediated by trust, while the effect of responsiveness on the customer loyalty is "partially" mediated by trust. The effect of convenience on customer loyalty is not mediated by trust.

\subsection{Implications and Suggestions}

We may understand why usefulness and security are fully mediated by trust. Since trust is the value that cannot be generated just in a short time, the construct in the model that is fully mediated by trust also cannot easily have impact on the loyalty in short-term. Clearly, the effort of improving usefulness by various product lines and effectively usable information, and security by information protection measures, takes time to gain trust from the customers. In reality, a customer cannot immediately believe that he is protected perfectly against risk of security such as uncertainty of transaction information and personal information. It explains, in the direct model, that security construct is rejected for customer loyalty. However, with the repeated purchase, the customer may get the trust, and this trust may bridge between the security provided by Lazada and the customer loyalty completely well. The more satisfying experiences a customer gets, the more he places his trust in the security of the web service platform. Contrary to the security, usefulness is always important for 
the customer to maintain customer loyalty. Therefore, Lazada should promote diverse construct of usefulness measures to create the customer relationship management in the short run, as well as to maintain it in the long term.

In this research, convenience refers to the benefits from the transaction cost saving: for example, the benefit of time saving when searching for products, benefit of time saving when minimizing delivery time (in comparison with the time of visiting an offline store for direct purchasing), and benefit of money saving when shopping online at a relatively lower price. Because transaction cost-saving benefits are the kind of value that the customers can recognize and get immediately in short-term, they are exempt from linking to "ongoing trust" in the long-term [41]. This can explain why convenience suffers no mediation effect from trust in the indirect model. In order to overcome this weakness, Lazada should make more effort to link this convenience even in the long term. Mileage or repurchase coupon could be good examples of this kind linking service from the short term convenience toward the long-term one to strengthen the role of trust even in the convenience.

Responsiveness shows an impact directly on customer loyalty, but also affects loyalty through trust, implying that loyalty is partially mediated by trust. Like convenience factor, Lazada should make more efforts for the customer to get more trust on the responsiveness leading the customer loyalty. Ironically, among three factors of mediated factors, assurance has the strongest influence on trust, implying that the effort of Lazada in assurance has the most significant effect in generating trust. The effort of Lazada in offering COD (cash on delivery) payment, return, and refund policy, as well as in certifying the products, has had a remarkable impact to appeal trust from customers. Accordingly, assurance could be considered as a strategic instrument to get more and more new customer participation, as well as a way of maintaining the loyalty from existing customers, especially with more emphasis on the long-term.

This paper found that without the strong role of e-trust, B2C intermediary such as Lazada could get successful operations in developing countries such as Vietnam because of its convenience factors. However, in order to achieve sustainable performance, the B2C intermediaries should make more proactive efforts to promote e-trust, because it will complement all the bottlenecks from the cultural or psychological barriers in the market. It is really true that even with their serious risk-avert attitude, most Vietnamese web-shoppers enjoy value creation based on relational support by an intermediary.

Choi and Jin found that this kind of on-going trust is very important in Chinese web marketing [31]. It implies that our findings emphasize not only the role of intermediary in the initial e-trust coming from the convenience, but also the sustainable performance of ongoing e-trust, especially in developing countries such as China and Vietnam. Therefore, the market-oriented policies of the developing government policies will certainly promote the acceleration of the online shopping innovation of the national economy. China showed that this kind of strong transformation, through intermediaries such as Alibaba, and now Vietnam, supported by Alibaba, the new owner of Lazada, will result in a new, successful story of a market-friendly, sustainable revolution in the web marketing through strong e-trust promotion activities [30,31].

\section{Conclusions}

In this paper, we proved that trust plays an important role in mediating the influence of usefulness, security, responsiveness, and assurance on customer loyalty, fully or partially, implying that the improvement of e-service quality should lead to an increase in credibility and customers' trust first. The analysis showed that customer loyalty is strongly linked to the consumers' trust, which means that in order to create sustainability for an e-commerce firm as an intermediary, it is crucial to consider trust as a vital element. As shown in the Figure 3, of reasons for not using e-commerce among Vietnamese people, product quality and security concern are the highest uncertainties perceived by Vietnamese e-commerce users. In order to overcome this kind of cultural background of risk-averse attitudes in Vietnam, online platform companies should make more effort, not only for the web service quality in 
the short run, but also more for the trust building in the long run. Based on above discussion, some suggestions could be proposed.

First, Lazada should continue improving their service quality and making long-term development strategy in terms of three factors: usefulness, security, and assurance. Because improving security along with enhancing level of trust is the only way to reach customer loyalty, Lazada should make more efforts to enhance its security.

Second, Lazada should pay more attention to the convenience factor. By fostering a delivery service and keeping a reasonably competitive price, etc., it should make the impact of convenience maintain even in the long term. It should be noticed that the competitive price must be equal to maintain the good quality of products.

Third, Lazada should take assurance as the most effective tactic at generating trust, because it shows the strongest impact on trust. Recently, Lazada has invested a large amount of money in marketing for the purpose of raising awareness among Vietnamese consumers as well as utilizing the efficiency of word-of-mouth or economy of sharing. It could encourage the Vietnamese consumer to be less reluctant towards online shopping and embrace the easy and effective online shopping environment.

Gupta, $\mathrm{Su}$, and Walter pointed out there is a difference in channel risk perceptions of consumers between online and offline channels, and in general, a negative association with channel switching tendency, yet the magnitude of the impact was small, implying that risk perceptions may play a minor role in the adoption of online shopping [42]. Su (2007) also emphasized that an increase in objective product information may lead to a dramatic increase in expected value choices and a corresponding decrease in brand-seeking and price-aversion choices [43]. This is true in our research as well. Even with convenience factors such as more reliable information certified by the e-tailer, the perceived risks could be reduced at least in the initial stage. It might be true that most developing countries may have a serious bottleneck in the e-business due to this missing link of trust in online shopping, and thus the government should promote a more reliable environment with strong regulations on the fraud and misleading behaviors, as well as diverse incentives for e-platform service providers such as Lazada to create and maintain trust more effectively. As shown in this paper, most developing countries were not aware of the e-trust, and thus it is very challenging tasks for these countries to take off toward the everyday online shopping effectively. In order to overcome these challenges, the role of e-platform service providers such as Lazada should be much more emphasized to create values based on their online network management.

Acknowledgments: This work was supported by an Inha University research grant.

Author Contributions: Yongrok Choi organized the models and finalized the paper, and Do Quynh Mai collected and analyzed the data and prepared the draft.

Conflicts of Interest: The authors declare no conflict of interest.

\section{References}

1. DeLone, W.H.; McLean, E.R. Measuring e-Commerce Success: Applying the DeLone \& McLean Information Systems Success Model. Int. J. Electron. Commer. 2004, 9, 31-47.

2. Choi, Y. Digital Business and Sustainable Development: Asian Perspectives; Routledge: New York, NY, USA, 2017.

3. E-commerce Foundation. Global B2C E-commerce Report 2016. Available online: https:/ /www.ecommercewiki. org/wikis/www.ecommercewiki.org/images/5/56/Global_B2C_Ecommerce_Report_2016.pdf (accessed on 17 November 2017).

4. Ministry of Industry and Trade. Vietnam e-Commerce Report 2015. Available online: http:/ /www.vecita. gov.vn/anpham/260/Vietnam-E-commerce-Report-2015/en (accessed on 20 November 2017).

5. Bhattacherjee, A. Understanding information systems continuance: An expectation-confirmation model. MIS Q. 2001, 25, 351-370. [CrossRef]

6. Statista. Vietnam e-Commerce Market. Available online: https://www.statista.com/outlook/243/127/ ecommerce/vietnam\# (accessed on 30 October 2017). 
7. Asia Plus Inc. Vietnam E-Commerce Market Survey. 2016. Available online: https://qandme.net/en/report/ Vietnam-EC-Market-Survey.html (accessed on 26 November 2017).

8. Saheli, R.C.; Arjun, K. Alibaba Buys Controlling Stake in Southeast Asian Retailer Lazada. CNBC. Available online: https:/ / www.cnbc.com/2016/04/12/alibaba-group-invests-1-billion-dollars-in-lazadagroup-and-eyes-southeast-asia.html (accessed on 24 November 2017).

9. DI Marketing. e-Commerce Usage in Vietnam 2016. Available online: https://www.slideshare.net/dimvn (accessed on 26 November 2017).

10. Thuy, M. Lazada Achieves Milestone of More than 110 Million Visits in First Half of 2015. Vietnam Investment Review. Available online: http:/ /www.vir.com.vn/lazada-achieves-milestone-of-more-than-110-millionvisits-in-first-half-of-2015.html (accessed on 28 November 2017).

11. Rose, F. The Economics, Concept, and Design of Information Intermediaries: A Theoretic Approach; Springer: Berlin/Heidelberg, Germany, 2012.

12. Choi, Y.; Lee, E.Y. Optimizing risk management for the sustainable performance of the regional innovation system in Korea through metamediation. Hum. Ecol. Risk Assess. 2009, 15, 270-280. [CrossRef]

13. Choi, Y. Sustainable Governance in Northeast Asia: Challenges for the Sustainable Frontier. Sustainability 2017, 9, 191. [CrossRef]

14. Choi, Y.; Sun, L. Reuse Intention of Third-Party Online Payments: A Focus on the Sustainable Factors of Alipay. Sustainability 2016, 8, 147. [CrossRef]

15. Oliver, R.L. Whence consumer loyalty? J. Mark. 1999, 63, 33-44. [CrossRef]

16. Srinivasan, S.S.; Anderson, R.; Ponnavolu, K. Customer loyalty in e-commerce: An exploration of its antecedents and consequences. J. Retail. 2002, 78, 41-50. [CrossRef]

17. Kuo, Y.F.; Hu, T.L.; Yang, S.C. Effects of inertia and satisfaction in female online shoppers on repeat-purchase intention: The moderating roles of word-of-mouth and alternative attraction. Manag. Serv. Qual. 2013, 23, 168-187. [CrossRef]

18. Choi, Y.; Gao, D. The role of intermediation in the governance of sustainable Chinese web marketing. Sustainability 2014, 6, 4102-4118. [CrossRef]

19. Kuan, H.H.; Bock, G.W.; Vathanophas, V. Comparing the effects of website quality on customer initial purchase and continued purchase at e-commerce websites. Behav. Inf. Technol. 2008, 27, 3-16. [CrossRef]

20. Wolfinbarger, M.; Gilly, M.C. e-TailQ: Dimensionalizing, measuring and predicting e-tail quality. J. Retail. 2003, 79, 183-198. [CrossRef]

21. Pasuraman, A.; Berry, L.L. SERVQUAL: A Multiple item scale for measuring customer perception of service quality. J. Retail. 1988, 64, 12-40.

22. Kim, C.; Galliers, R.D.; Shin, N.; Ryoo, J.H.; Kim, J. Factors influencing Internet shopping value and customer repurchase intention. Electron. Commer. Res. Appl. 2012, 11, 374-387. [CrossRef]

23. Carter, L.; Schaupp, L.C. Relating Acceptance and Optimism to E-File Adoption. Int. J. Electron. Gov. Res. 2009, 5, 62-74. [CrossRef]

24. Lin, H.F. The impact of website quality dimensions on customer satisfaction in the B2C e-commerce context. Total Qual. Manag. Bus. Excell. 2007, 18, 363-378. [CrossRef]

25. Ribbink, D.; Van Riel, A.C.; Liljander, V.; Streukens, S. Comfort your online customer: Quality, trust and loyalty on the internet. Manag. Serv. Qual. 2004, 14, 446-456. [CrossRef]

26. Chiu, C.M.; Chang, C.C.; Cheng, H.L.; Fang, Y.H. Determinants of customer repurchase intention in online shopping. Online Inf. Rev. 2009, 33, 761-784. [CrossRef]

27. Yang, H.E.; Wu, C.C.; Wang, K.C. An empirical analysis of online game service satisfaction and loyalty. Expert Syst. Appl. 2009, 36, 1816-1825. [CrossRef]

28. Anderson, R.E.; Swaminathan, S. Customer satisfaction and loyalty in e-markets: A PLS path modeling approach. J. Mark. Theory Pract. 2011, 19, 221-234. [CrossRef]

29. Hong, I.B.; Cho, H. The impact of consumer trust on attitudinal loyalty and purchase intentions in B2C e-marketplaces: Intermediary trust vs. seller trust. Int. J. Inf. Manag. 2011, 31, 469-479. [CrossRef]

30. Pennanen, K.; Tiainen, T.; Luomala, H. A Qualitative Exploration of a Consumer's Value-Based e-Trust Building Process: A Framework Development. Qual. Mark. Res. 2007, 10, 28-47. [CrossRef]

31. Choi, Y.; Jin, J. Is the web marketing mix sustainable in China? The mediation effect of dynamic trust. Sustainability 2015, 7, 13610-13630. [CrossRef] 
32. Henseler, J.; Ringle, C.M.; Sinkovics, R.R. The use of partial least squares path modeling in international marketing. In New Challenges to International Marketing; Emerald Publishing: Bingley, UK, 2009; pp. 277-319.

33. Chen, S.C.; Lin, C.P. The impact of customer experience and perceived value on sustainable social relationship in blogs: An empirical study. Technol. Forecast. Soc. Chang. 2015, 96, 40-50. [CrossRef]

34. Chin, W.W.; Newsted, P.R. Structural equation modeling analysis with small samples using partial least squares. In Statistical Strategies for Small Sample Research; Sage Publications, Inc.: Thousand Oaks, CA, USA, 1999; Volume 1, pp. 307-341.

35. Fornell, C.; Larcker, D.F. Evaluating structural equation models with unobservable variables and measurement error. J. Mark. Res. 1981, 19, 39-50. [CrossRef]

36. Hair, J.F.; Black, W.C.; Babin, B.J.; Anderson, R.E. Multivariate Data Analysis: A Global Perspective; Pearson Education: London, UK, 2010.

37. Campbell, D.T.; Fiske, D.W. Convergent and discriminant validation by the multitrait-multimethod matrix. Psychol. Bull. 1959, 56, 81-105. [CrossRef] [PubMed]

38. Fornell, C.; Bookstein, F.L. Two structural equation models: LISREL and PLS applied to consumer exit-voice theory. J. Mark. Res. 1982, 19, 440-452. [CrossRef]

39. Baron, R.M.; Kenny, D.A. The moderator-mediator variable distinction in social psychological research: Conceptual, strategic, and statistical considerations. J. Personal. Soc. Psychol. 1986, 51, 1173-1182. [CrossRef]

40. Sobel, M.E. Asymptotic confidence intervals for indirect effects in structural equation models. Sociol. Methodol. 1982, 13, 290-312. [CrossRef]

41. MacKinnon, D.P.; Lockwood, C.M.; Hoffman, J.M.; West, S.G.; Sheets, V. A comparison of methods to test mediation and other intervening variable effects. Psychol. Methods 2002, 7, 83-104. [CrossRef] [PubMed]

42. Gupta, A.; Su, B.C.; Walter, Z. An Empirical Study of Consumer Switching from Traditional to Electronic Channel: A Purchase Decision Process Perspective. Int. J. Electron. Commer. 2004, 8, 131-162.

43. Su, B.C. Consumer Strategies of E-tailer Choice at the Online Shopping Comparison Sites. Int. J. Electron. Commer. 2007, 11, 137-162. [CrossRef]

(C) 2018 by the authors. Licensee MDPI, Basel, Switzerland. This article is an open access article distributed under the terms and conditions of the Creative Commons Attribution (CC BY) license (http:/ / creativecommons.org/licenses/by/4.0/). 